THE HARVEIAN ORATION
CONDITIONS OF THE PULMONARY
CIRCULATION.

Delvered at the Royal College of Physicuans, on October 18th, 1890, Bx JAMES ANDREW, M.D.Oxon., F.R.C.P., Physician to St. Bartholomew's Hospital.

THE pleasure, Sir, with which I learnt from your lips that I had this year to discharge the time-honoured function of Harveian Orator was largely alloyed with dismay at the difficult nature of the task before me.

My predecessors have been so numerous (this commemoration of benefactors is held to-day for the 172nd time), they have also been so well equipped for the work by literary skill, by training, and by knowledge, that it might well be thought that nothing could be easier or more certain to be successful than to follow faithfully in their steps ; but, unfortunately, the very number of my predecessors and their individual excellence render this course impossible; for it is one thing to imitate with more or less success the style and method of a great writer or speaker, it is another and a very different matter to reproduce his actual words and facts, to publish, so to speak, a new edition of his work with no real change except in the title page.

Now Harvey's shield has been burnished so often, and with such sharp-sighted devotion, that no spot or stain remains upon it; his claim to be the discoverer of the circulation of the blood has been fully established, his writings have been found to be pregnant with the ideas and discoveries of later generations-nay, more, the man himself has been proved to be not less than his work. His great discovery was no chance find, no mere lucky hit, but the natural outcome of his genius and of his time. How, then, can the belated Harveian Orator of the present day hope to add even one fresh pebble to the cairn which the love and the labour of generations have raised over the "immortal " Harvey?

On beginning my quest for something new, it soon became clear that, of the two fields more especially open to me, Sir James Paget had practically exhausted that of St. Bartholomew's Hospital in his Records of Wm. Harvey in Extracts from the Journals of St. Bartholomew's Hospital, with Notes, by James Paget, published in 1846 ; but I still hoped to discover, by the help of learned friends. some hitherto unnoticed records of Harvey's life in Oxford ; nor, indeed, is it imposeible that such do exist, although I have failed to unearth them. The sole result of my search-and this I owe to the kindness of the present. Warden of Merton College-is the following brief report, in the Register of Merton College, of Harvey's speech to the Fellows on April 11th, 1645, two days after his admission to the Wardenship.

"Dominus Custos Convocatis in Altâ Aulâ Sociis hæc verba ad illos fecit. Forsitan decessores custodiam Collegii ambiisse, ut exinde se locupletarent, se verò longè alio animo nimirum ut Collegio lucro et emolumento potius foret; simulque socios ut concordiam amicitiamque inter se colerent, sedulo solliciteque hortatus est"

This fixes the exact date of Harvey's admission to the Wardenship. namely, on April 9tb, 1645-O. S. And there is another reason for my dwelling on what may seem to be a matter of but small importance.

On the strength of this short entry in the College Register it has been stated that Harvey delivered a somewhat "Pharisaical" epeech to his Fellows. Now, if we bear in mind the violent passions aroused on both sides during the civil war-nay, even if we judge his words by the modern standard of parliamentary language as established during this last session-Harvey can scarcely be held to bave indujged in excessive abuse of his predecessors, including Sir Nathaniel Brent, or to have said ton much in praise of himself. The exhortations to concord and good fellowship come with double weight from a man who cared first for learning and science, and then made provision, also, for a general feast once every year, and, "at every meeting once a month. for a small collation, as the President shall think fit, for the entertsinment of such as come.". By a very natural feeling on the part of the College, the lecture and feast, which Harvey guilelessly founded in commemoration of the benefactors of the College, have come to be devoted almost entirely to the commemoration of the most illustrious benefactor of them all-himself.

The value of Harvey's great discovery can scarcely be exaggerated, either in itself or as an illustration of scientific method and work, or in its effect on the course and development of physiological studies. There is no need to $d w e l l$ on points such as these before this audience. We are all of one mind in the matter.

But, besides these great things, Harvey's writings contain also many things of less importance indeed, but yet well worthy of our consideration; for example, we may find in them no doubtful indications of the wise and prudent advice which he would have given us for the abatement of some, at least, of the evils under which our profession labours at the present day. Let me give one or two illustrations of my meaning taken from the first sixteen chapters of the treatise on the Motion of the Heart and Blood.

In the first rank of the ills which jbeset the profession $I$ :do not hesitate to place the enormous amount of so-called medical literature. Were it all good there would still be quite enough of it; but could we get rid of the vain repetitions of all the books which contain little or no original work, and are too often the damaged seed, not the fruit, of practice and of a ripe experience-could we get rid of all the clinical observations, with the idle theories based upon them, which from their imperfections are simply misleading - could this be done, the residue;would no doubt be small, might indeed bear much the same proportion to the original mass as fine gold does to the ore from which it has been extracted, but it would be far more valuable than anything which medical literature in its present form can offer to us.

There is one publication which I regard with especial horrorthe "invaluable "Index Medicus. I find that the volume for 1889 (the last completed, but not the greatest of eleven volumes) contains the names of not fewer than 13,870 contributors. Now the index of the Index fully bears out the supposition that each pair of contributors represents not less than three communications, and thus we have a total of not less than 20,000 contributions to medical science for last year. I have much pleasure in admitting that many of them are short, but then it must not be overlooked that many of them are substantial treatises in two volumes or more. That one volume of the Index alone contains sufficient material for a small library of monographs and systematic treatises, which a very moderate amount of mechanical industry could easily put together. I venture to think that no small part of medical literature would never have been written had its authors given heed to Harvey's words at the end of the Dedication of his treatise on the Motion of the Heart and Blood. "My dear colleagues," he writes, "I had no purpose to swell this treatise into a large volume by quoting the names and writings of anatomists, or to make a parade of the strength of my memory, the extent of my reading, and the amount of my pains; because I profess both to learn and to teach anatomy, not from books but from dissections ; not from the positions of philosophers. but from the fabric of Nature. I avow myself the partisan of truth alone; and I can, indeed, say that I have used all my endeavours, bestowed all my pains, on an attempt to produce something that should be agreeable to the good, profitable to the learned, and useful to letters."

Again, a very common reproach cast upon our profession is that we pretend to be, and are not, scientific - that, to quote an old sarcasm, our occupation consists in putting drugs of which we know notbing into bodies of which we know less. There is just sufficient truth in such criticisms to make them somewhat unpleasant to those for whose good they are no doubt intended; but they derive the keenness of their sting from our own shortcomings and mistakes. We claim too much and do too little for medicine; we forget that our duty as medical men is twofold-to practise an art and to study and advance a science; that we are bound to make the best use we can of the knowledge within our reach, and if possible to add to it in the using; but this last is not our chief duty. We dare not sacrifice the interests, the life, of one single patient to the advancement of science. If our conscience were to cease to forbid us to do this, then the sooner modern science deprives us once for all of such a treacherous guide the better for the world will it be. A man may be a first-rate practitioner and yet have no title whatever to be ranked among scientific physiologists, as a sailor may be a first-rate navigator without being in any proper sense of the words a scientific astronomer or Works of William Harvey, M.D, By Robert Willis, M.D. Sydenham Society, 
mathematician or physicist. Yet, in spite of this admission, the physiologist ought to be the last to taunt us with ignorance and empiricism, for his own science would be far more imperfect than it now is were it stripped of all that it owes to the results of medical and surgical practice.

One of the best, if not the best, definitions of "medicine" is that which describes it as "applied physiology." If we fail to attain to that ideal ; if we are compelled daily to act upon probabilities in place of scientific certainties, then the blame must rest at least as much on the physiologist as on ourselves. He fails to supply us with the knowledge which we require and which he alone can give us. Medicine is thus but one of many instances of an art stunted by the insufficient development of the science with which it is connected and on which it rests. I do not mean insufficient in a general sense, but insufficient for certain special purposes.

Permit me to anticipate a very possible criticism upon what $I^{\prime}$ have just said. It may be thought that my words are an unfair attack upon physiology, and that, safe from immediate contradiction, I have sought to defend medicine by abusing the very science to which, of all sciences, we are most deeply indebted. Now, if I have indeed done this thing. I have been guilty of the basest ingratitude; I have ignored the splendid services which physiology has rendered to medicine-services which we believe to be but the earnest of others yet more splendid in the near future. If physiology is, as it seems to me, not yet equal to all the requirements of medicine, that is certainly not due to the indolence or weakness of those who cultivate it, but to the inherent difficulties of their task. They have done all, and more than all, which we could have looked for. But at the sight of sickness which we cannot heal we grow impatient, unreasonable, and long for knowledge not yet within the reach of man. We even refuse to recognise the wisdom of those who decline to attempt to solve by scientific means problems not yet ripe for such solution. However, although the object matter with which we deal lends itself unwillingly to strict scientific method; although from its very nature we are unable to submit it to direct experiment, except in most imperfect fashion, it may still be studied and observed in a scientific spirit. Every case of disease may be-ought to be-looked upon as an experiment in practical physiology, an experiment carried out with transcendent skill by Nature herself, but which she leaves it to us to observe, to register, and to interpret.

Now in this matter of scientific observation it cannot be denied that we fall very far short of what we might accomplish. It will do our profession no good to dwell upon the legitimate excuses which may in part explain our failure : rather let us acknowledge that failure, and use our utmost efforts to remove it. Nor are leaders wanting who can teach us how this may best be done. We need not look beyond the circuit of our college to find men who can, and do, carry on their daily work in this scientific spirit, approving themselves herein worthy followers of the example of Harvey.

Surely we cannot regard Harvey the physician as less scientific than Harvey the anatomist and physiologist, when we find him showing from certain familiar reasonings that the circulation is matter both of convenience and necessity. In his hands, the physical signs of an aneurysm, the effect of extreme cold, the phenomena which attend "contagions, poisoned wounds, the bites of serpents and rabid animals, lues venerea, and the like"-all these are made to supply probable and cogent arguments for the truth of the doctrine of the circulation of the blood.

Were our clinical knowledge as carefully accurate in its statement of facts, were it always used as soberly and to as good purpose as Harvey's was, then there would be, there could be, no outcry raised against us on the score of credulity, or of want of scientific method. When he had arrived at a knowledge of the circulation of the blood by means of anatomical researches and vivisections, Harvey at once applied this knowledge to the explanation of clinical phenomena up to that time inexplicable. He then used the fact that this explanation was a simple and adequate one as a new and strong argument for the truth of his discovery.

That this intimate connection, this solidarity, between physiology and medicine is no longer recognised so fully as it once was is much to be regretted, for it is injurious to both lines of study, and has arisen, at least in part, from faults on both sides. But this view must not be pushed too far. We must not lose sight of the fact that the relationship between physiology and medicine has in many ways greatly changed during the last 250 years, and that such change is a necessary consequence of the progress made by physiology.

In Harvey's time, in any classification of the sciences, physiology might have been regarded as a department of medicine. I need scarcely say that now the reverse would be the case. The two deal, it is true, with the same object-matter, for there is no physiological fact or law which is without some bearing upon medicine; and again every medical fact or generalisation, even those most purely empirical, is more or less important to physiology. But their aims and methods are so different that they tend inevitably to become more and more sharply differentiated from each other.

The goal of physiology is truth; that is, perfectly trustworthy knowledge of a certain class of facts and laws, and this independently of any use, good or bad, to which that knowledge may be put. The goal of medicine is power, that is, ability to manipulate certain natural forces in such fashion as to produce certain effects. No doubt theoretically the two ends coincide, and we may hope that in some remote future they will do so in reality and perfectly. For the present we must be content with having in one direction much knowledge which confers little or no power, and, on another side, very imperfect knowledge which yet brings with it very great power, too often ill-directed.

Again, their methods are different. Physiology by slow degrees has come to rely more and more on purely scientific modes and instruments of research, and to apply them by preference to matters which can be brought to the test of direct experiment. Medicine, on the other hand, has no choice but to remain, so far as it has a scientific side, a science of observation; for anything like effective investigation of the matters with which it deals by direct experiment is impossible. As physiology slowly reduces to order the apparently hopeless confusion of so-called vital actions the easiest questions are attacked and answered first, and thus those which have to be faced later in their turn are more and more difficult, more and more refractory to scientific analysis. Now, these more difficult questions are often of vital importance to medicine, and in them lie dormant vast possibilities of increased knowledge of the nature of disease, of increased power over it. And yet, from the great difficulty of subjecting them to experiment, physiology may seem for a time to fail us, and the task of employing physiological results to explain clinical facts or to form the basis of rational treatment becomes harder than ever.

This brief sketch of the relations between physiology and medicine, and of the change which has gradually taken place in these relations-a change leading in appearance and for a time to a great widening of the interval which separates two sister sciences -is, I well know, very imperfect and full of contentious matter, but it arose naturally and took its colour from my own experience, and especially from that of the last few months.

Not the least important part of the charge of the Harveian Orator is that which directs him to exhort the Fellows and Members of the College to search and study out the secrets of Nature by way of experiment. It is a little embarrassing for the scholar to find himself called upon to instruct his teachers, but I think that I cannot employ the time at our disposal better or in a manner more agreeable to the declared intention of the great founder of this lecture than by laying some recent experience of my own before you. I do this with much diffidence and a full conscioueness of my own inability to deal satisfactorily with the weighty matters involved in it, and would ask you not to overlook my shortcomings, but to correct them.

In the course of last winter it was my fortune, whether good or bad I know not, to meet with several severe cases of bæmoptysis, two or three of which, in spite of my best efforts, ended fatally. About the same time I rashly undertook to give a lecture on the treatment of hæmoptysis at the City of London Hospital for Diseases of the Chest. My attempt to instruct others was repaid by the bighest reward which can fall to the lot of a would-be teacher: the conviction of $\mathrm{my}$ own ignorance. I found, not for the first time, what many of you must also have found, that the treatment of hæmoptysis is eminently unsatisfactory ; in fact that, beyond a few general measures and simple remedies, all tending to reduce blood pressure in the vascular system as a whole, it was very doubtful whether our present supposed knowledge enabled us to do any good at all to our patient. I was reduced to a state of therapeutic despair, and even suspected that of the drugs commonly employed some might be actually injurious. The same feelings, the same sense of helplesenese, had 
often passed over me before, but without any good result. This time the stimulus, perhaps, of St. Luke's day was stronger, and I tried to look for a remedy. The following enumeration of remedies which, at different times, and on more or less satisfactory grounds, have been supposed to be of value in the treatment of hæmoptysis, is taken from a well-known standard work on Pharmacology, Therapeutics, and Materia Medica. Long as it is, a less critical author might have made large additions to it; nor have I any fault to find with the place which it and similar lists occupy in therapeutical writings; they are a necessary part of the work, and in this case the writer has been careful to add to its value by drawing special attention to those means in which he believes that the most reliance may be placed. It is noteworthy that he does this in three cases only, namely, gallic acid, hamamelis, and lead acetate.

"Remedies for Hamoptysis.-Acetic acid, aconite, alum, ammonium chloride, arnica, astringent inhalations, barium chloride, chlorodyne, chloroform to outside of chest, copaiba, copper sulphate, digitalis, dry cups to chest, ergot and ergotinin, ferric acetate, ferri persulphas, gallic acid, hamamelis, hot-water bag to spine, ice, ipecacuanha, iron and absolute rest, lead acetate, matico, morphine, opium, phosphoric acid, potassium bromide, potassium chlorate, potassium nitrate, pyrogallic acid, silver oxide, sodium chloride in drachm doses, subsulphate of iron, sulphuric acid, tannin, tr. laricis, turpentine, veratrum viride."

Now, on looking through a long list like this, one's first and last thought is that it gives us a very good illustration of the truth of the old axiom that, when many drugs are supposed each to cure one and the same disease, we may safely hold that few, if any, of them have the least influence over it. Some of these before us have been proposed on chemical, some on nervous or vascular-nervous theories, and the claims of a few have been supported by direct physiological experiment; but all in the last resort profess to have had their worth determined by clinical observation of the effects which follow upon their employment. In a matter of this kind, however, clinical observation has to be received with great distrust, and must be carefully sifted. It is not sufficient to quote a long list of cases in a large percentage of which complete recovery followed the exhibition of certein remedies. With this we want a control list of the issues of cases which have run their course without any treatment whatever; and, so far as hæmoptysis, or, indeed, any other disease is concerned, no such control list exists. Experience in large out-patient hospital practice for many years taught me that cases of hæmoptysis, of all degrees of severity, are of very frequent occurrence, in which recovery takes place without any medical interference, and that, too, under very unfavourable conditions of life. And, further, that this vis medicatrix natura, this self-help, shows its power most clearly in what may seem to be the worst cases: that is, a patient has a sudden, rapid, profuse hæmoptysis; he remains at home, and the bleeding does not return, or only after a long interval, to be reckoned by weeks, months, or even years: or, again, so soon as, or even before, the hæmorrhage has ceased, he is seen by a doctor, who injects ergotine subcutaneously, and believes, pardonably enough, that the injection has stopped the bleeding. But in each case the syncope following the sudden loss of even a comparatively small quantity of blood has given suflicient pause to the circulation to favour the formation of a clot in the ruptured ressel itself, or in the bronchus or vomica with which it communicates.

We cannot judge of the effect of remedies without some knowledge of the natural history of the diseases in which they are employed. Perhaps in the case of hrmoptysis the same mistake namely, that of attributing the natural termination of a pathological process to the effect of remedies-is repeated which up to a few years ago was made in that of pneumonia, another pulmonary affection; and of the specific fevers. Clinical observation has so far failed to give anything like scientific proof of the supposed influence of certain drugs upon hæmoptysis-that is, upon the pulmonary circulation.

After all, it is not very surprising that clinical observation has failed to give definite results in this matter. The difficulties in the way of investigating the relative effect of drugs by any means at the command of the medical practitioner may well be in many cases insuperable. But it is disappointing to find that the drugs which have been proved by direct physiological experiment to be at any rate likely, on the theories of those who propose them, to be of service in hæmoptysis, do not come more distinctly to the front, do not establish a stronger claim to our confidence than the rest. It almost seems as if in this case we could not expect to receive any help from physiology. Happily this is not so. Physiology is at last overcoming the great difficulties in the way of accurate determination of variations in the pulmonary circulation and of their causes; and the results already obtained, imperfect though they be, are of sufficient interest and importance to justify me in bringing them before you to-day.

The relations between the systemic and the pulmonary circulations in respect of blood pressure and other conditions form a large, and it may be a very fertile, province of vascular physiology, which has been almost entirely ignored by medicine, and treated by physiology so slightly that it has yielded but few, if any, results of value to medicine. I do not know any treatise on systematic medicine, any monograph on diseases of the lungs, which contains even a hint that the two systems may be to some extent independent of each other, and may react in different ways to the same stimuli, and in the same ways to different stimuli.

Throughout medicine assumes that indications for the treatment of pulmonary diseases may be taken from the systemic pulse as directly and with as much confidence as in the case of erysipelas or of enteritis. The pulmonary circulation is treated as if it were simply the termination of the systemic venous trunks into which a small additional pump-the right ventricle with its valvular arrangements - has been introduced, with the effect of preventing undue stagnation of the blood current.

And this view does contain a half truth. For example, in many cases of long standing and extreme mitral incompetence wo can trace, after death, every where as we pass backwards against the blood stream from the left auricle to the large systemic veins, conclusive evidence of the existence during life of undue vascular tension. In the left auricle, pulmonary veins, pulmonary artery, the large systemic veins, in the hepatic veins, we find thickening and opacity of the inner cost of the vessels, in fact, atheroma; and this, too, in cases where the systemic arteries-its most froquent seat-may be all but free from it. Throughout this tract it would seem that the same condition of undue pressure has prevailed, and that if any forces exist tending to produce inequalities of pressure in different regions they must be very feeble ones. Of course this is an extreme, though not infrequent, case, and cannot be regarded as throwing much useful light upon the state of things in health or even in less severe cases of disease.

Anyhow, medicine, if it recognises any mechanism in the pulmonary circuit analogous to the vasomotor arrangements in the systemic side, has not thought it worth while, or has not been able, to make any practical use of such knowledge.

Now physiology has not done quite so much as we might wish, but it has certainly accomplished more than medicine has even attempted. It has taught us the relatively low blood pressure in the pulmonary artery, and has even succeeded in directly measuring this blood pressure, with the result of proving that the relation between the pulmonary and carotid pressure varies in different species of animals, being in the rabbit $1: 4.2$; in the cat, $1: 5.3$; in the $\operatorname{dog}, 1: 3.05$.

Again, physiology has established the existence in one speciesthe dog - of vasomotor nerves, which exercise more or less control over the blood flow through the pulmonary artery.

In a valuable paper communicated to the Koyal society in February, 1889, Dr. Bradford, Dr. Dean, and Mr. George Henry Lewes arrived at the following conclusions: "The pulmonary vessels of the dog are supplied with vasomotor fibres, leaving the cord through the roots of the uppermost dorsal nerves. No efferent vasomotor fibres have been detected in the vagus nerve.

"The pulmonary circulation is comparatively independent of the sitemic, and alterations in the blood pressure of the latter must be of large amount to affect the pulmonary blood pressure. It is probable that no rise of aortic pressure can materially influence the pulmonary blood pressure, unless it is so great in amount or duration that the heart muscle and valves are unable to cope with it, and so an actual regurgitation is produced. It is possible that the pulmonary blood pressure can also be affected by rises of systemic pressure causing venous distension, and hence an increased supply to the right side of the heart.

"Finally, although it is undoubted from the results of this research that the mammalian pulmonary vessels receive vacomotor nerves, yet it is probable that the vasomotor mechanism is but poorly developed as compared with that regulating the systemic arteries. In this respect it may be that the pulmonary system holds an intermediate position between the systemic arteries on the one hand and the veins on the other"

The experiments on which these conclusions rest are also in- 
teresting from other points of view. I will mention one which has a close connection with my present purpose. "When the peripheral end of such a nerve as the sixth or seventh dorsal is excited, a rise of pressure in both the pulmonary and aortic system is observed. The pulmonary rise, although considerable, for example, 3 or $4 \mathrm{~mm}$. Hg., is not out of proportion to the aortic rise, which, with these nerves, may be as much as 30 or $40 \mathrm{~mm}$. Hg. On ascending, however, very different results are obtained. Thus in one case the fifth dorsal gave an aortic rise of $10 \mathrm{~mm}$. Hg. only, but the pulmonary rise was $3 \mathrm{~mm}$. Hg.

"Clearly the latter was not a passive effect of the former.

"In another case the fourth dorsal gave an aortic rise of $20 \mathrm{~mm}$. Hg. and a pulmonary rise of $4 \mathrm{~mm}$. Hg. Perhaps, however, the most marked and conclusive result is seen with the third dorsal nerve. This nerve frequently causes no aortic rise, and, indeed, sometimes actually a fall ; for example, $10 \mathrm{~mm}$. Hg., but in both these cases there is a distinct pulmonary rise of 3 or $4 \mathrm{~mm}$. Hg."

Thus far, then, we have learnt : 1 . That the pulmonary circulation, like the systemic, is to a certain extent under the control of vasomotor nerves. 2. That the two vasomotor systems are closely connected with each other, inasmuch as direct irritation of the same nerve or of the same part of the spinal cord produces a simultaneous effect on both sets of vessels. 3. That this effect may be either a rise or a fall in pressure in both, or a rise in one and a fall in the other. The next step was to ascertain whether the effect of certain drugs is the same for each upon the two circuits. The facts just mencioned make it, to say the least, highly probable that this is not the case, but the question could only be answered satisfactorily by direct experiment.

Through the kindness of Dr. Bradford, of University College Hospital, and of Dr. Bokenham, assistant to my colleague, Dr. Lauder Brunton, in the science workroom of St. Bartholomew's Hospital, I am enabled to lay before you the following statements as to the comparative effect of certain substances upon the two circulations. Their researches were carried on entirely independently of each other, and yet their results are practically identical.

Muscarin.-In the British Mrdical Journal for November 14th, 1874, Dr. Lauder Brunton gives the following account of the action of muscarin on the heart. Having thoroughly narcotised a rabbit with hydrate of chloral, he commenced artificial respiration, and opened the thorax. Both sides of the heart seemed to be equally filled, the veins only moderately distended, and the lungs rosy. On injecting a little muscarin into the jugular vein everything at once changed. The lungs became blanched, the left side of the heart became small, the right side swelled up, and the vena cava became greatly distended. After a short time a little atropine was injected into the jugular vein, and everything instantly returned to its normal condition. The left side of the heart regained its former size, the right side diminished, the distension of the veins disappeared, and the blanched lungs again assumed a rosy hue. Distrusting his own personal observation, Dr. Brunton got two observers who knew nothing about the experiment and repested it before them, noting down their observations, which agreed exactly with his own. It is all but impossible, I think, either to doubt the accuracy of the record of this experiment or to attribute the pbenomena observed, especially the simultaneous distension of the pulmonary artery and the blanching of the lungs, to any other cause than the action of vasomotor nerves. Subsequent observers seem to have failed to obtain the striking effects witnessed by Dr. Lauder Brunton, but his account is substantially confirmed by Dr. Bokenham, who tells me that muscarin in a small dose causes rapid fall in the carotid pressure, with, in most cases, a rise in the pulmonary pressure. This rise, however, is not long maintained. The pressure in the pulmonary artery sinks to normal, whilst that in the carotid more slowly rises to it original level. A large dose seems to produce paralysis of the heart and rapid fall of pressure in both circuits.

Amyl Nitrite given by inhalation caused rapid fall in carotid pressure, with simultaneous marked rise in pulmonary pressure. Carotid pressure then rises, and during this rise the pulmonary pressure resumes its original level.

Nitro-glycerine.-In the cat ${ }^{2}$ gr. produced a temporary great fall of the carotid, with a slight rise of the pulmonary pressure. When, however, the carotid fall had reached its lowest point the pulmonary pressure also fell. The carotid pressure then rose, but not to the normal figure. At the beginning of this rise the pulmonary pressure showed some tendency to fall, but remained nearly constant. In the dog to gr. produced a primary fall in the carotid, with little or no effect on the pulmonary pressure. A subsequent gradual rise of the carotid pressure then took place, with a very slight fall of pulmonary pressure during the greater part of the rise.

Digitalis.-Digitalin caused steady rise of blood pressure both in carotid and pulmonary arteries, with great slowing of pulse. Tinct. digitalis: In doge, slight fall in carotid pressure following soon after injection. At this time practically no effect on pulmonary pressure. Following this a steady rise in both pulmonary and carotid blood pressure. Inf. digitalis: In cats, primary rise in blood pressure both in carotid and pulmonary arteries, followed by slight but more permanent rise. (The primary rise here was probably due to the fact that a large quantity of fluid had to be introduced, as the same result followed the injection of a similar quantity of water.)

Tinct. Strophanthi. - In cats, a small dose (namely, $m$ i-ii) produced a primary fall of pressure in both carotid and pulmonary arteries, and a subsequent rise in pressure almost up to normal Heart at same time slow and irregular. A large dose produced first a great rise of carotid pressure, the pulmonary pressure sinking slightly at first and then rising slightly. Then great quickening of heart with steady fall of pressure in carotid; the pulmonnary falling to, but not below, its original level.

Ergot produces primary rise in pulmonary, with simultaneous fall in carotid, pressure. This rise, however, is of short duration. Subsequently both pressures rise.

Aconite produces fall in pressure in both carotid and pulmonary arteries.

Strychnine, in botb carotid and pulmonary arteries, produced a rise in pressure especially marked in the pulmonary.

Chloroform both pressures fall together.

Ether.-Both pressures rise together.

Atropine (Sulphate) produces first a steady fall in carotid pressure, the pulmonary sinking at the same time, but in much less degree. During this period the heart is slowed and the vagus nerve is excitable. Next pressure rises in both, and pulse becomes more frequent, the inhibitory power of the vagus being gradually abolished. When the pressure reaches its highest point, the heart cannot be stopped by stimulation of the vagus, and a second dose of atropine will have no further effect.

Quebracho (Tincture) produces in carotid a primary fall, in pulmonary a slight rise, followed in the carotid by a steady rise to a higher point than normal, whilst in the pulmonary artery the higher level already reached is maintained ; finally, in the carotid the pressure becomes very great, whilst in the pulmonary artery it does not rise above the slightly higher level it reached at first.

In the graphic records of these experiments there are many things of great interest, but, from lack of time, I have confined myself to one point only, namely, the pressure relations of the two circuits to each other; and it is clear that in some cases these relations, under the influence of the same drug, vary in a manner which could scarcely have been ascertained without the aid of direct experiment. It is difficult to arrive at any classification of them beyond this; that, if the systemic pressure rises, then the pulmonary pressure also rises; if the eystemic pressure falls, then the pulmonary may either rise or fall. And even this is only true of the primary effect of the drug, for among the later effects, for example, in the case of amyl nitrite, and to a less extent in that of nitro-glycerine, the pressure in the pulmonary artery may fall whilst that in the carotid is rising.

Again, although it might be impossible from these pharmacological researches alone to prove the existence of pulmonary vasomotor nerves, still given the fact that such nerves do exist-and this has now been established-then some of their results seem to find their best, perhaps only, explanation on the vasomotor-nerve theory. Of course. in the production of these variations of pressure vasomotor influence is not the only one at work. They may be due, for example, to increased force of the heart's action, or to causes as purely mechanical as anything can be which takes place within a living organism, as, for example, when a block in the aorta raises the pulmonary pressure, whilst a block on the right side of the heart, or in the lungs, lowers the systemic pressure. Still the knowledge that certain conditions of pressure in the pulmonary circuit may be determined by the administration of certain drugs, even though we may be left in ignorance of the exact mode in which this effect is brought about, may be of great value.

But before attempting to appraice the value to medicine of 
physiological (pharmacological) researches such as these, I have a mournful duty to perform. I must say "good-bye " to my trusty physiological guides, who have already fallen a little behind, and decline to go with me any further. They tell me-and from the point of view of their science it is their plain duty to do so-that we have no right to assume that the results of $f$ xperiments on animals, performed under conditions very different from those of healthy life, would hold good in the case of man; that no scientific proof of the existence of pulmonary vasomotor $n$ rves in the human subject has been given, and that it is very unlikely that such proof ever will be given. Thus it is difficult to imagine a more perfectly unscientific proceeding than to attempt to arrive at indications for treatment by virtue of assumptions which have no scientific basis whatever. That to do so is to step from the rock on to, and into, the quicksand. Well, until physiology holds out to us a more hopeful prospect than this, and more effectual aid than she does now, the path of our duty leads strajght through the quicksand. We must make the most careful and the best use of the data, such as they are, which we possess; and may then, after all, entertain good hopes that the conclusions which we may come to, although, logically, they must always remain probable only, may yet be true.

My evidence in the matter is prejudiced; personally, I confess that I should like to have myself a vasomotor pulmonary arrangement with the latest improvements up to date. Such a mechanism, if it exists, must be a great comfort and advantage to its possessor. It would regulate, from the most favourable standpoint, the supply of blood to the left side of the heart, meeting and satisfying the various and ever-varving needs of the organism with the right quantity of freshly aërated blood, and at the same time safeguarding the delicate tissue of the lungs from the dangers which wait upon congestion. For when, as must of ten happen, the blood accumulates to more or less excess in the pulmonary circuit and in the great systemic venous trunks, then the action of pulmonary vasomotor nerves would, pro tanto, tend to transfer the increase of pressure from the former to the large veins of the trunk, and to easily distensible organs such as the spleen and liver.

In suppcrt of this, let me refer you again to Dr. Lauder Brunton's experiments with muscarin, which prove that-at all $\epsilon$ vents, in some of the lower animals-a mechanism exists which is capable of accomplishing a great deal in the direction of relieving the pulmonary veins and capillaries from undue pressure. Of course this line of argument-a very tempting one to some people-is utterly wortbless, and if no other and better proof can be adduced, the case must be given up. Such an argument, however, moy be found in the fact that pulmonary vasomotor nerves of more or less activity have been demonstrated in the dog-that is, certain nervous arrangements have been found to exist in that animal in connection with the function of respiration, a function necessary to life and carried on by very similar mechanism in many thousands of species. Is it not highly probable that this same nervous mechanism exists in all, or almost all, animals whose respiratory apparatus is similar and their type of development not inferior to that of the particular species in which its existence has been demonstrated?

So far as man is concerned, the argument gains additional strength; its conclusion attains to a higher degree of probability when we remember that it is impossible to doubt the existence in him of systemic vasomotor nerves at least as fully organised, as richly endowed, as those which have been demonstrated in lower animals by direct experiment, and to which in man, as in the dog, a pulmonary vasomotor system would be a fitting complement. Surely there is uniformity in organic not less than in inorganic nature, a uniformity which enables us to forecast with confidence the existence of similar functions and structures in animals specifically or generically allied.

I have no wish to deny that conclusions arrived at by such a process are, after all, only probable, but their probability is eminently reasonable if due care be taken in the verification and use of the facts on which the $y$ rest; the argument must start from facts, recognised as such by science, and not from mere hypotheses. In this way we may bope to maintain the wholesome and necessary relations between medicine and physiology, for it will be an evil day for both if ever the results of laboratory work are held to have no bearing upon medical practice.

The not improbable hypothesis that pulmonary vasomotor nerves exist in man may be used to explain some otherwise puzzling facts in connection with disease of the heart, and esp96 cially of the mitral orifice. Cases are met with not infrequently in which the primary seat of the obstruction to the blood flow is on the left side of the heart, and there is no evidence of anything wrong on the right side. At the same time the cervical veins are distended, there is a certain amount of general anasarca, and exaggerated loudness of the second sound of the heart in the second left intercostal space makes it probable that there is undue pressure in the pulmonary artery. And yet the lungs, in whose veins and capillaries the effects of the cardiac difficulty must, on $\theta$ would think, be first felt, show but slight, if any, signs of congestion.

No doubt many explanations might be given of this state of things, but none meet the conditions of the problem more exactly than contraction of the pulmonary arterioles under some vasomotor influence. Indeed, so far as the vessels are concerned, we may fairly compare the effect on the; pulmonary artery of obstruction on the left side of the heart with that of cirrhosis of the kidneys on the systemic arteries.

There is one conclusion to be drawn from the results of the pharmacological researches just laid before you which is if no small practical interest. If it be true, to use the statement i.: one of the best monographs on diseases of the lungs, that "it is of great importance to relieve blood pressure in hæmoptysis," then aconite ought to be a much more efficient remedy for that affection than ergot.

On this occasion, your Harveian Orator enjoys great latilude in the choice of subjects and in his mode of treating them. I trust that in your judgment $I$ have not abused that privilege. The relation of physiology to medicine, at all times a matter of supreme importance to our profession, is especially so at present, when from the rapid scientific development of physiology the two lines of study are sear by year becoming more and more widely separated, not to say antagonistic - a state of thirgs whinh is distinctly injurious to the scientific claims of medicine. The remedy is in our own hands; it is our duty now more than ever to work out and to utilise to the utmost the medical aspects of each fresh physiological advance, and we must bring our best powers to this task.

I have ventured to bring under your notice the "conditions of the pulmonary circulation" as a subject in which much yet remains to be done by physiology, and from which medicine may hope to derive no little benefit. Let me add that the results of such a research may be great or small, but until they have been realised by science, and bave found their place in medicine, Harvey's labours will not have yielded up their full fruit.

\section{REPORTS TO THE}

\section{SCIENTIFIC GRANTS COMMITTEE OF THE} BRITISH MEDICAL ASSOCIATION.

\section{PRELIMINARY REPORT ON \\ ASEPTIC AND SEPTIC SURGICAL CASES, INCLUDING TRAUMATIC TETANUS, GANGRENE, AND ACUTE EPIPHYSITIS. ${ }^{1}$}

\section{BY C. B. LOCKWOOD, F.R.C.S.,}

Surgeon to the Great Northern Hospital ; Senior Demonstrator of Anatomy and of Operative Surgery in St. Bartholomew's Hospital.

THE following gives the results of the bacteriological examination of a number of surgical cases. The work was begun to ascertain whether my methods of wound treatment excluded microbes, and to show the effects of their presence or absence upon the clinical history of the cases. Some of the traumatic infective diseases have also been investigated, and points of interest which have arisen will be mentioned.

Before proceeding it is necessary to premise that for present

1 This work was assisted with a grant from the Scientific Grants Committee of the British Medical Association. I am also greatly indebted to the Committee of the Great Northern Hospital for the use of a room and other conveniences. 